\title{
The R304X mutation of the aryl hydrocarbon receptor interacting protein gene in familial isolated pituitary adenomas: Mutational hot-spot or founder effect?
}

\author{
G. Occhi1, M.L. Jaffrain-Rea2,3, G. Trivellin1, N. Albiger1, F. Ceccato1, E. De Menis4, M. Angelini², \\ S. Ferasin1, A. Beckers5 , F. Mantero1, and C. Scaroni1 \\ ${ }^{1}$ Endocrinology Division, Department of Medical and Surgical Sciences, Padua Hospital/University, Padua; ${ }^{2}$ Department of \\ Experimental Medicine, University of L'Aquila, L'Aquila; ${ }^{3}$ Neuromed Institute IRCCS, Pozzilli; ${ }^{4}$ Department of Internal Medicine, \\ General Hospital, Montebelluna (Treviso), Italy; ${ }^{5}$ Endocrinology, Centre Hospitalier Universitaire de Liège, University of Liège, \\ Liège, Belgium
}

\begin{abstract}
Background: Mutations in the aryl hydrocarbon receptor interacting protein (AIP) gene have been described in about $15 \%$ of kindreds with familial isolated pituitary adenomas and in a minority of early onset sporadic pituitary adenomas (PA). Among the AIP mutations reported so far, the R304X (AIPR304X) represents, together with the "Finnish mutation" Q14X, the most common one. Methods: Three AIPR304X Italian families, including a newly reported kindred, have been genotyped for 12 genetic markers surrounding the AIP gene in order to look for a potential founder effect in Italy. Disease penetrance and genotype-phenotype correlations were also addressed. Results: Analysis of chromosome 11' genetic markers revealed a common haplotype in 2 AIPR304X kindreds originat-
\end{abstract}

\section{INTRODUCTION}

Familial isolated pituitary adenoma (FIPA) is an hereditary syndrome defined as 2 or more patients affected with pituitary adenomas (PA) in the same kindred, with no clinical and/or genetic evidence of multiple endocrine neoplasia type 1 (MEN1) or Carney Complex (1). PRLand/or GH-secreting PA account for $75 \%$ of FIPA, which are classified as homogeneous or heterogeneous, depending on the presence of a single or multiple PA phenotypes in the same family, respectively $(1,2)$.

In 2006, a germline inactivating mutation (Q14X) in the aryl hydrocarbon receptor interacting protein (AIP) gene was identified in a large kindred with GH and/or PRL-secreting PA originating from Northern Finland (3) and in $13 \%$ of acromegalic patients from a population-based cohort from the same geographical area, as a possible consequence of a founder effect $(3,4)$. At the same time, an AIP R304X mutation (AIPR304X) was reported in an Italian FIPA kindred (3). Further studies revealed that AIP mutations were present in 15\% of FIPA families, including up to $50 \%$ of those with homogeneous somatotropinomas, AIP-mutated patients being significantly younger at diagnosis and presenting with larger tumors than non-

\footnotetext{
Key-words: AIP, FIPA, founder effect, haplotype analysis, pituitary adenoma.

Correspondence: G. Occhi, PhD, Department of Medical and Surgical Sciences, Via Ospedale 105, 35128 Padova, Italy.

E-mail: gianluca.occhi@unipd.it

Accepted January 6, 2010.

First published online March 30, 2010
}

ing from central Italy. Overall, 17 mutations carriers were identified, including 7 patients and 10 unaffected subjects, respectively, arguing in this case for a disease penetrance of $41 \%$. Mean age at diagnosis was $19.1 \pm 6.7 \mathrm{yr}$ old, with females tending to be older than males. Though most PA were somatotropinomas (6/7), a great variability in disease severity was observed, even between subjects sharing the same at-risk haplotype. Conclusion: These data provide strong evidence for a new founder effect of the AIPR304X mutation in central Italy and the observed variations in disease severity point out the role of additional genetic or environmental factors in such kindreds. (J. Endocrinol. Invest. 33: 800-805, 2010)

๑2010, Editrice Kurtis

AIP-mutated patients (5). Conversely, AIP mutations were very rarely found in sporadic cases (6), with the exception of young patients with somatotropinomas (7-9). Yet, the AIPR304X mutation has been reported in 4 European FIPA kindreds $(3,5,10)$, including 2 unrelated Italian families $(3,5)$, and in a young patient with apparently sporadic acromegaly (7), representing, together with the "Finnish mutation" $(3,4)$, the most common one. In this paper, we report a novel Italian FIPA family carrying the AIPR304X mutation. In order to look for a possible founder effect in Italy, haplotypes around the AIP gene in $11 \mathrm{q} 13$ were compared in this kindred and in the 2 previously reported AIPR304X Italian kindreds $(3,5)$. In addition, we joined our efforts to address disease penetrance and search for genotype-phenotype correlations in such kindreds.

\section{MATERIAL AND METHODS \\ Patients}

An heterogeneous 2-generation FIPA family presenting with a $\mathrm{GH}$ - and a PRL-secreting PA was studied at the Endocrinology Unit in Padua, and a familial screening was proposed (see pedigree in Fig. 1A). In brief, clinical examination was followed by hormonal testing as previously described (11). After an AIPR304X mutation was recognized in both patients, 3 additional mutations carriers were identified. A 2-h oral glucose tolerance test (oGTT) was performed in these subjects, replaced by a determination of $\mathrm{GH}$ every 30 min for $3 \mathrm{~h}$ in diabetic patients (12) and a pituitary magnetic resonance imaging (MRI) was proposed. The 2 previously reported AIPR304X Italian FIPA families $(3,5)$ 
were referred by the Neuromed Institute of Pozzilli (Family 2, Fig. 1B) and the Hospital of Treviso (Family 3), respectively, and included upon informed consent for haplotype analysis. Most individual characteristics of these patients were previously reported in details $(5,13,14)$.

\section{AIP sequencing and loss of heterozygosity studies}

Genomic DNA was isolated from the peripheral blood using the QIAcube extractor (Qiagen, Milan, Italy) following the manufacturer's instructions and PCR amplified with primers spanning untranslated regions, coding regions and intron-exon boundaries of the AIP gene. PCR primers tailed with an M13 forward or reverse primer sequence on the 5 '-end were designed by PRIMER 3 (http://frodo.wi.mit.edu/). Primers sequences and PCR conditions are available upon request. DNA sequencing was performed using the BigDye 3.1 Termination Chemistry (Applied Biosystems, Monza, Italy) on an ABI 3730XL DNA sequencer (Applied Biosystems) using universal M13 primers.
A tumor sample obtained from family 1's proband at transsphenoidal surgery was collected in RNAlater (Applied Biosystems) and tumor DNA was extracted using Trizol reagent (Invitrogen, Milan, Italy) with a modified protocol (http://www.mrcgene.com/ tri.htm). Loss of heterozygosity (LOH) was studied by AIP sequencing at the corresponding mutation position as described above, and analysis of informative microsatellite markers flanking the AIP gene as described below.

\section{Haplotype analysis}

Available members of families 1 and 2, and family 3's proband, were genotyped using 12 microsatellite markers surrounding both AIP and MEN1 genes, which are located respectively at 64.3 and $67.0 \mathrm{Mb}$, and 1 single nucleotide polymorphism (SNP) (rs4084113) (Table 1). Genetic markers' primers sequences were obtained from the UCSC Genome Browser website (http://genome.ucsc.edu/) and a previous publication (3). Additional tandem repeats were identified by Tandem Repeat

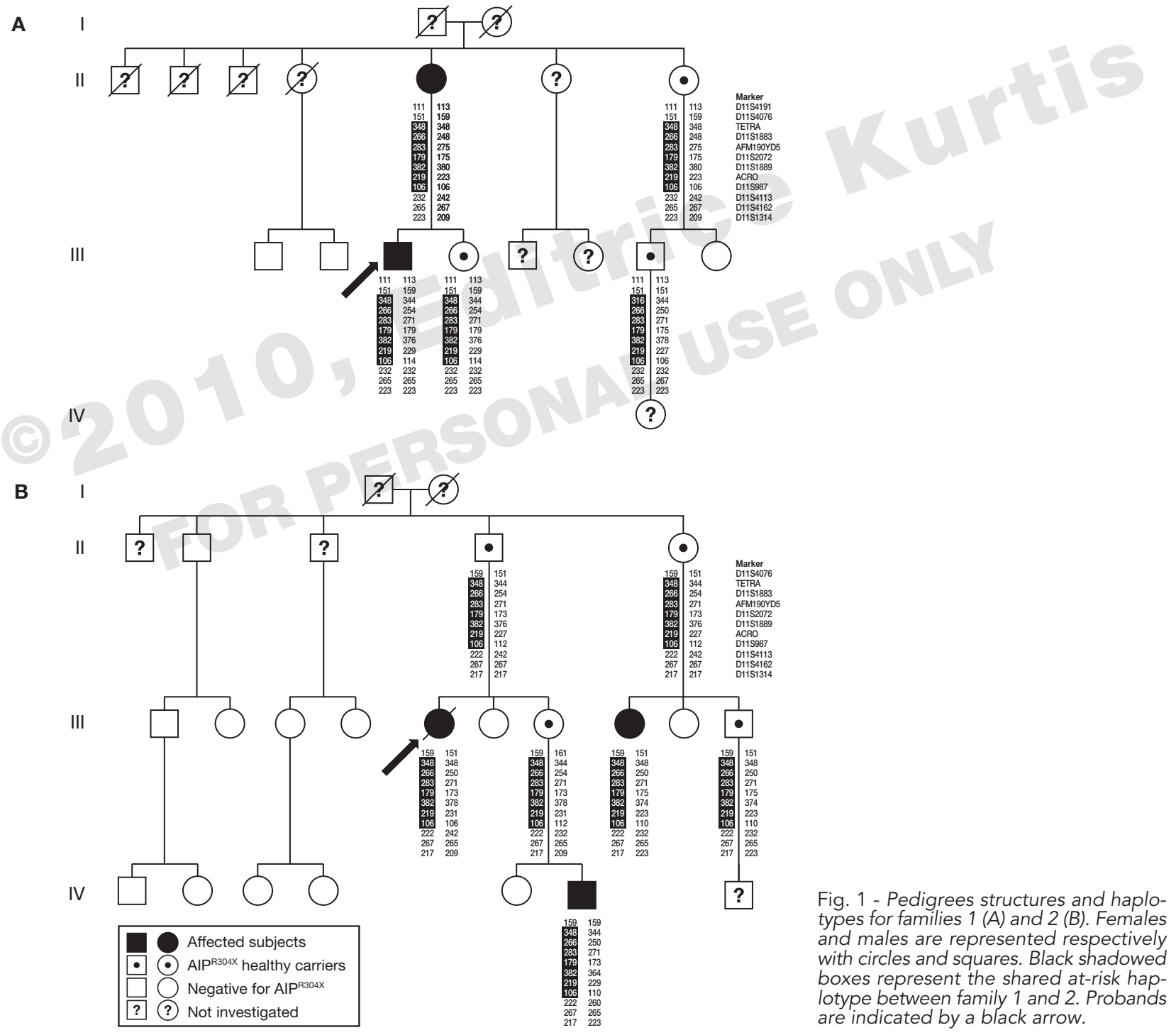


Table 1 - Molecular markers on chromosome 11 and haplotype data in the Italian AIPR304X families. For families 1 and 2 the at risk haplotype shared by all mutation carriers is reported and the common disease-associated haplotype is indicated by asterisks.

\begin{tabular}{|c|c|c|c|c|}
\hline \multirow[t]{2}{*}{ Marker } & \multirow{2}{*}{$\begin{array}{c}\text { Physical } \\
\text { Location (Mb) }\end{array}$} & \multicolumn{3}{|c|}{ Haplotypes } \\
\hline & & Family 1 & Family 2 & Family 3 \\
\hline D11S4191a & 59.75 & 111 & 111 & $\mathrm{n} / \mathrm{a}$ \\
\hline D11S4076a & 61.12 & 151 & 159 & 151159 \\
\hline m_11TETRA@61.73 & 61.73 & $348^{*}$ & $348^{*}$ & $\mathrm{n} / \mathrm{a}$ \\
\hline D11S1883a & 63.13 & $266^{*}$ & $266^{*}$ & 254260 \\
\hline AFM190YD5 & 66.67 & $283^{*}$ & $283^{*}$ & 271271 \\
\hline D11S2072 & 66.98 & $179 *$ & $179^{*}$ & 173173 \\
\hline rs4084113 & 67.01 & $T^{*}$ & $T^{*}$ & $\mathrm{CC}$ \\
\hline D11S1889a & 67.07 & $382^{*}$ & $382^{*}$ & 378378 \\
\hline ACRO_CHR11_28b & 67.21 & $219^{*}$ & $219^{*}$ & 229231 \\
\hline D11S987a & 67.64 & $106^{*}$ & $106^{*}$ & 114114 \\
\hline D11S4113a & 68.52 & 232 & 222 & $\mathrm{n} / \mathrm{a}$ \\
\hline D11S4162a & 70.65 & 265 & 267 & 265267 \\
\hline D11S1314a & 72.00 & 223 & 217 & 223223 \\
\hline
\end{tabular}

aAllele size standardized on a known CEPH subject (1347-2). bVierimaa et al., 2006 (3). n/a: not evaluated.

Finder (http://tandem.bu.edu/trf/trf.html). Markers were PCRamplified from genomic DNA, separated on an ABI 3730XL DNA sequencer, and analyzed with Peak Scanner v1.0 software (Applied Biosystems). For 8 markers, the CEPH 1347-2 control was included to standardize allele sizes (Table 1). For SNP genotyping, direct sequencing of AIP exon 3 was performed.

\section{Statistical analysis}

Data are expressed in mean \pm SD Mann-Whitney test was performed using Statistica 7.1 (StatSoft, Italy). A p-value $\leq 0.05$ was considered significant.

\section{RESULTS}

Patients and tumors characteristics in family 1

The heterogeneous FIPA family identified in Padua, originating from central Italy, is currently composed of an acromegalic male patient and his mother, affected by a prolactinoma.

\section{Case1}

The index case (Fig. 1A, subject III3) was referred to our Endocrinology Unit in 2007 at the age of $32 \mathrm{yr}$. Age at onset of the first acromegalic features, based on patient interview, was $19 \mathrm{yr}$. Mean GH plasma concentration was $9 \mu \mathrm{g} / \mathrm{l}$ (7 basal determinations, normal range $0-5 \mu \mathrm{g} / \mathrm{l})$, IGF-I $1008 \mu \mathrm{g} / \mathrm{l}$ (normal range for sex and age 97-306 $\mu \mathrm{g} / \mathrm{l}$ ) and PRL over $1000 \mu \mathrm{g} / \mathrm{l}$ (normal range 5-15 $\mu \mathrm{g} / \mathrm{l}$ ), respectively. Hypogonadotropic hypogonadism and impaired glucose tolerance with hyper-insulinemia were also present, and 2 benign colonic polyps were found by systematic endoscopy. MRI revealed a pituitary macroadenoma $(12 \times 10 \mathrm{~mm})$. Combined medical treatment with somatostatin analogs [octreotide long-acting release (LAR) $30 \mathrm{mg} / \mathrm{month}$ ] and dopamine agonists (cabergoline up to $2 \mathrm{mg} /$ week) was started, with tumor shrinkage of about $30 \%$ and partial biochemical control of the disease. Eight months later, he underwent transsphenoidal surgery, with a post-operative persisting disease $(\mathrm{GH}$ nadir after oGTT $3.66 \mu \mathrm{g} / \mathrm{l}$, IGF-I $896 \mu \mathrm{g} / \mathrm{l}$, and PRL $700 \mu \mathrm{g} /$, respectively) and pharmacological treatment was re-started. A mixed GH/PRL-secreting PA was confirmed by immunohistochemistry and AIP immunostaining, performed as previously described (15), was moderately positive (Fig. 2). Because partial resistance to the previous treatment was confirmed (IGF-I 814 $\mu \mathrm{g} / \mathrm{l}, \mathrm{PRL} 128 \mu \mathrm{g} / \mathrm{l}$ ), pegvisomant (10 mg/day sc) was added with a rapid decrease in IGF-I levels to $385 \mu \mathrm{g} / \mathrm{l}$ in 1 month.

\section{Case 2}

The 64 yr-old mother of the index case (Fig. 1, subject II7) had a past history of hyperprolactinemia with galactorrhea and menstrual irregularity at age of $30 \mathrm{yr}$, successfully treated with dopamine-agonists until menopause at 53 yr. In 2008, she had persisting mild asymptomatic hyperprolactinemia (prolactin $50 \mu \mathrm{g} / \mathrm{l}$ ) and a 3$\mathrm{mm}$ pituitary microadenoma was present at MRI. Because

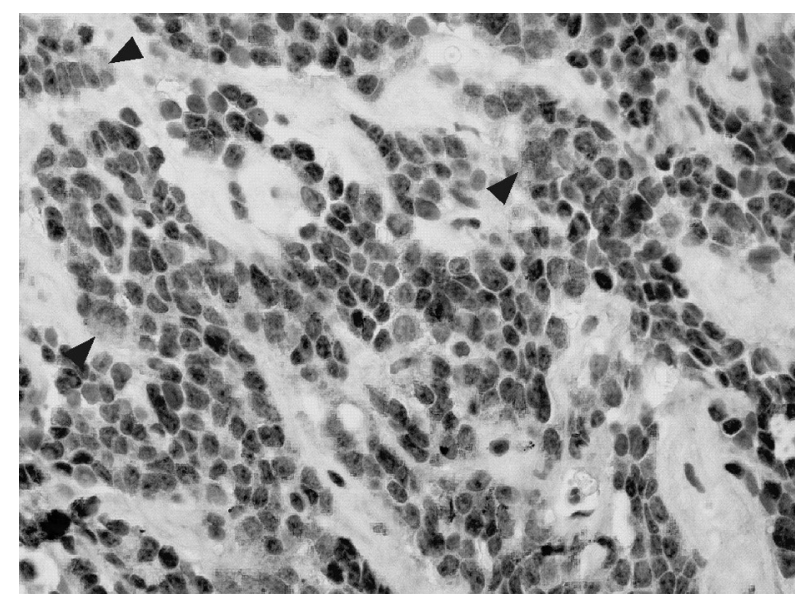

Fig. 2 - Cytoplasmic AIP immunostaining of pituitary adenoma specimen of family's 1 proband. The AIP-positive areas are indicated with black arrows. 
of Type 2 diabetes (glycated hemoglobin 7.2\%), a 3-h $\mathrm{GH}$ profile was performed, with mean plasma $\mathrm{GH}$ $0.29 \pm 0.14 \mu \mathrm{g} / \mathrm{l}$. Plasma IGF-I was normal for age (120 $\mu \mathrm{g} / \mathrm{l})$ Follow-up of the lesion was thus proposed without treatment.

\section{AIP sequencing and LOH analysis in family 1}

Family 1's proband was first investigated for germline AIP mutations, and a c.910C $>\mathrm{T}$ transition, leading to the truncating R304X mutation was identified (Fig. 3A, B). LOH study confirmed the loss of the wild-type allele (Fig. 3C) from markers D11S4076 to D11S987 (data not shown). Familial screening further identified the AIPR304X mutation in his affected mother and in 3 relatives $(2$ female and 1 male, aged 58, 27, and $31 \mathrm{yr}$ old, respectively) who had neither clinical, biochemical nor radiological evidence of pituitary disease.

\section{Genotyping}

Because the AIPR304X mutation was identified in three apparently unrelated Italian FIPA families, we wished to find out whether the c.910T mutated allele had a common origin or was the result of a mutational hot-spot. To address this issue, 12 microsatellite markers around AIP and MEN1 genes were first analyzed in all consenting patients and relatives. In family 1 , an at risk haplotype of at least $12 \mathrm{Mb}$ was found to segregate in all mutation carriers. Interestingly, the AIPR304X mutation carriers in family 2, but not the family 3's proband, shared the same at risk alleles for 6 markers (Table 1, Fig. 1), strongly arguing for a founder effect common to families 1 and 2 . Because the genetic length of the shared region is inversely proportional to the age of the founding event, a SNP (rs4084113) located within AIP intron 3 was also genotyped. As showed in Table 1, the c.910T allele was associated with the at-risk haplotype in families 1 and 2, whereas family 3 's proband is an homozygous carrier of the c.910C allele, further supporting the hypothesis of an independent mutational event occurred in this later family.

\section{Characterization of AIPR304X mutated subjects}

Bio-clinical features of AIPR304X patients and carriers identified in families 1, 2, and 3 were evaluated comparatively. Whereas family 1 was heterogeneous for somatotropinoma and prolactinoma, families 2 and 3 were homogeneous for somatotropinomas. Overall, among the 17 AIPR304X mutation carriers identified so far, 7 had developed evidence of PA (4/9 women and 3/8 men, respectively), so that disease penetrance could currently be estimated in this cohort to $41 \%$. A consistent variability in clinical disease expressivity was observed in

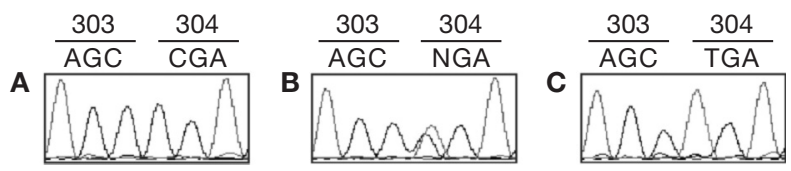

Fig. 3 - Sequence electropherograms showing c. 910 nucleotide in a healthy wild type subject $(A)$, in germinal $(B)$, and in tumoral DNA of the proband of family 1 (C). these patients, though age at first symptoms was $\leq 30 \mathrm{yr}$ in all cases (mean 19.1 \pm 6.7 , range 8-30) and tended to be younger in male patients $(15.0 \pm 6.1$ vs $22.3 \pm 6.0$ in females, p: ns). Accordingly, gigantism was present in 2 males. Most PA were macroadenomas (71\%), including 2 giant adenomas (13). From a functional point of view, $\mathrm{GH}$ and GH/PRL-secreting PA were present in 57\% (4/7) and in $29 \%(2 / 7)$ of cases, respectively, and confirmed by immunohistochemistry after surgery, the latter case being a non-operated microprolactinoma (14\%).

From a therapeutic point of view, only $1 / 6$ patients who underwent surgical treatment had a successful outcome. Noteworthy, this patient (Fig. 1B, subject IV-4) was the 3 rd symptomatic case in a FIPA kindred with aggressive tumors (13). Incipient gigantism could be recognized at the age of $8 \mathrm{yr}$ thanks to clinical screening by auxological follow-up, a few months before the AIPR304X mutation was identified in this kindred.

All patients received pharmacological therapy, and only $1 / 6$ patients treated with somatostatin analogues, experienced disease control after 6 yr of exclusive post-operative treatment (octreotide LAR 20 mg/monthly). The remaining patients required combined therapy with dopamine-agonists, pegvisomant and/or radiotherapy for the control of post-operative GH/IGF-I hypersecretion. Three patients received radiotherapy, resulting in long-term disease control with tumor shrinkage and progressive hypopituitarism, including GH deficit in all cases (follow-up 12 to $13 \mathrm{yr}$ ). Family 2's proband recently died at the age of $32 \mathrm{yr}$ from acute polmonitis; she had been suffering in the last years from severe obesity-related respiratory insufficiency and disease-related secondary epilepsy.

\section{DISCUSSION}

Up to $5 \%$ of PA occur in familial settings (2). In about $40 \%$ of these cases, the pituitary lesion is the unique clinical manifestation described and this entity is referred to as FIPA (16). In the last years, the identification of germline mutations in the AIP gene as a predisposition gene in Finnish patients $(3)$ as well as in FIPA kindreds $(3-8,10)$ has provided a novel important tool for the evaluation of such patients.

In the present study, genetic and bio-clinical features of a novel Italian FIPA family carrying an AIPR304X mutation have been described and compared with the two AIPR304X unrelated Italian kindreds previously reported $(3,5,13,14)$. The AIPR304X mutation leads to the premature termination of translation resulting in protein truncation and consequent impairment of protein-protein interactions. In particular, integrity of the C-terminal -helix is essential for AIP to stabilize the aryl hydrocarbon receptor (AHR) in a multimeric cytoplasmic complex (17, 18) and, though AIP is generally expressed in AIPR304X PA $(10,19), A H R$ is destabilized in the corresponding tumors (19). Indeed, in agreement with $\mathrm{LOH}$ in $11 \mathrm{q} 13$ in most PA related to AIP mutations (3, 6, 8-10), and as further demonstrated herein, only the truncated AIPR304X protein is expressed at a somatic level (19).

Together with the Finnish founder mutation AIPQ14X which, similarly to other disorders, is likely to reflect a founder ef- 
fect in this population $(3,20)$, the AIPR304X currently represents the most frequently reported AIP mutation in FIPA. Yet, it has been reported in four apparently unrelated European families, including 2 Italian kindreds $(3,5,10)$, and in a sporadic French acromegalic patient (7). Thus, the family reported herein is the third apparently unrelated Italian AIPR304X kindred, and a collaborative study was thought in order to look for a potential common ancestor. Data obtained on haplotyping around the AIP gene revealed that the 2 kindreds, who probably originated from the same region of central Italy, shared about $6 \mathrm{Mb}$ on chromosome $11 \mathrm{q}$, supporting the presence of a founder effect in this region - namely Lazio. Conversely, the nucleotide substitution observed in family 3 could be ascribed to an independent mutational event. Because AIPR304Q mutations have also been described in 3 sporadic patients with acromegaly $(6,7,21)$, one with Cushing's disease $(6)$, and in a FIPA family (10), originating from at least 3 different countries, the presence of a mutational hot-spot at codon 304 is likely. From a genetic point of view, this could be related to the presence of two CpG dinucleotides located within a CG-rich region. Indeed, DNA methylation of intragenic $\mathrm{CpG}$ followed by deamination of 5-methylcytosine to thymine, is the most frequent cause of point mutations in humans, accounting for about $20 \%$ of all base substitutions causing genetic diseases (22). Of note, a second mutational hot spot, AIPR271W, has been recently identified in 3 FIPA kindreds (23).

Because of the small size of FIPA families and the number of AIP mutations reported so far $(2-10,15,16,23-25)$, potential genotype-phenotype correlations have been rarely addressed $(15,23,25)$. In this collaborative study we compared the clinical presentation of 7 AlPR304X patients and evaluated the penetrance of the disease among AIPR304X carriers according to familial screening. The penetrance of PA in AIPR304X carriers observed in our cohort of patients, was slightly higher than reported by Naves et al. (15) in a large Brazilian family carrying the AIPE174fs mutation ( $41 \%$ vs $33 \%$, respectively). Actually, this value might still be underrated since 1 healthy carrier is younger than $30 \mathrm{yr}$ of age (the age at first symptoms in our oldest affected patient) and therefore could theoretically develop a pituitary tumor. Taking into account data reported on obligated mutation carriers by Leontiou et al (15), up to 16 out of 28 AIPR304X carriers identified so far have developed clinical evidence of PA (57\%). However, studies on obligated mutation carriers only may overestimate disease penetrance by excluding unrecognized healthy carriers, and the true penetrance can be best approached by extensive familial studies as performed herein. In any case, further studies both in highrisk families and in a general population are mandatory for a more reliable penetrance estimation.

Differences in AIP-related disease penetrance or expressivity may in part depend on the functional consequences of the mutation itself (i.e localization and type of missense mutation, length of the truncated protein). Interestingly, significant phenotypic variability could be observed even among AIPR304X kindreds, as illustrated herein by the severe phenotype observed in family 2 as compared to family 1, despite a common genetic background was assessed by haplotyping. Intra-familial variability can also be present, with an heterogeneous FIPA pattern observed herein in family 1 and in 2 previously reported kindreds (10), and an homogeneous pattern for somatotropinomas in families 2 and 3, respectively. Disease variability points out the role of additional factors, such as environmental factors or genetic modifiers, in determining the clinical phenotype (26). However, all AIPR304X patients reported so far $(3,5,7,10,13,14$, this study) had $\mathrm{GH}$ and/or PRL-secreting PA, with a large predominance of somatotropinomas and a young age at disease onset (46.7\% and $93.3 \%$ under 20 and 30 yr-old, respectively, vs $6.7 \%$ over $40 \mathrm{yr}$-old). Although the frequent male predominance reported in patients with AIP mutations has not been observed in AIPR304X patients taken as a whole [8 males (M)/10 females (F) vs 41M/16F (25)], the mean age at diagnosis also tends to be lower in males $(17.4 \pm 6.1$ vs $24.9 \pm 7.4 \mathrm{yr}$ in female patients, $p=0.10)$. Accordingly, gigantism is rare in females (10). It is remarkable that, in the present series, only the young boy diagnosed with pre-pubertal incipient gigantism could be successfully operated by transsphenoidal surgery. This strongly supports early genetic testing in these kindreds (27), as already proposed for MEN1, where pituitary evaluation is advised since early childhood (28).

Another important point is potential resistance to pharmacological therapy. In fact, somatotropinoma resistance to somatostatin analogues, has already been reported in acromegalic patients carrying different AIP mutations (8), suggesting that an altered AIP function and/or expression might in some way influence somatostatin receptor signaling.

In conclusion, while further supporting the presence of a mutational hot spot at AIP codon 304, our data also provide the first genetic evidence for a founder effect of the AIPR304X mutation in a region of central Italy. In order to further define its magnitude and favor precocious diagnosis in potentially affected AIPR304X carriers, we suggest that special attention should be paid to young acromegalics in this region. The potential severity and common pharmacological resistance of AIPR304X related somatotropinomas further supports AIP mutational screening in such patients.

\section{ACKNOWLEDGMENTS}

We would like to acknowledge the "Fondazione Carlo Ferri per la Prevenzione e la Diagnosi Precoce dei Tumori, Monterotondo (RM), Italy for continuous support and Dr. G. Vazza for helpful discussion about founder effects.

\section{REFERENCES}

1. Daly AF, Jaffrain-Rea ML, Ciccarelli A, et al. Clinical characterization of familial isolated pituitary adenomas. J Clin Endocrinol Metab 2006, 91: 3316-23.

2. Beckers A, Daly AF. The clinical, pathological, and genetic features of familial isolated pituitary adenomas. Eur J Endocrinol 2007, 157: 371-82.

3. Vierimaa $\mathrm{O}$, Georgitsi M, Lehtonen R, et al. Pituitary adenoma predisposition caused by germline mutations in the AIP gene. Science 2006, 312: 1228-30.

4. Aaltonen LA. Aryl hydrocarbon receptor-interacting protein and acromegaly. Horm Res 2007, 68 (Suppl 5): 127-31.

5. Daly AF, Vanbellinghen JF, Khoo SK, et al. Aryl hydrocarbon receptor-interacting protein gene mutations in familial isolated pitu- 
itary adenomas: analysis in 73 families. J Clin Endocrinol Metab 2007, 92: 1891-6.

6. Georgitsi M, Raitila A, Karhu A, et al. Molecular diagnosis of pituitary adenoma predisposition caused by aryl hydrocarbon receptorinteracting protein gene mutations. Proc Natl Acad Sci U S A 2007, 104: 4101-5.

7. Cazabat L, Libe R, Perlemoine K, et al. Germline-inactivating mutations of the aryl hydrocarbon receptor-interacting protein gene in a large cohort of sporadic acromegaly: mutations are found in a subset of young patients with macroadenomas. Eur J Endocrinol 2007, 157: 1-8.

8. Barlier A, Vanbellinghen JF, Daly AF, et al. Mutations in the aryl hydrocarbon receptor interacting protein gene are not highly prevalent among subjects with sporadic pituitary adenomas. J Clin Endocrinol Metab 2007, 92: 1952-5.

9. Georgitsi M, De Menis E, Cannavò S, et al. Aryl hydrocarbon receptor interacting protein (AIP) gene mutation analysis in children and adolescents with sporadic pituitary adenomas. Clin Endocrinol (Oxf) 2008, 69: 621-7.

10. Leontiou CA, Gueorguiev M, van der Spuy J, et al. The role of the aryl hydrocarbon receptor-interacting protein gene in familial and sporadic pituitary adenomas. J Clin Endocrinol Metab 2008, 93: 2390-401.

11. Scaroni C, Selice R, Benedini S, et al. Adrenal morpho-functional alterations in patients with acromegaly. J Endocrinol Invest 2008, 31: 602-6.

12. Grottoli S, Razzore P, Gaia D, et al. Three-hour spontaneous GH secretion profile is as reliable as oral glucose tolerance test for the diagnosis of acromegaly. J Endocrinol Invest 2003, 26: 123-7.

13. Ferretti $\mathrm{E}$, Jaffrain Rea $\mathrm{ML}$, Asteria $\mathrm{C}$, et al. Two familial giant pituitary adenomas associated with overweight: clinical, morphological and genetic features. Eur J Endocrinol 2001, 144: 227-35.

14. De Menis E, Prezant TR. Isolated familial somatotropinomas: clinical features and analysis of the MEN1 gene. Pituitary 2002, 5: 11-5.

15. Naves LA, Daly AF, Vanbellinghen JF, et al. Variable pathological and clinical features of a large Brazilian family harboring a mutation in the aryl hydrocarbon receptor-interacting protein gene. Eur J Endocrinol 2007, 157: 383-91.
16. Daly AF, Tichomirow MA, Beckers A. Update on familial pituitary tumors: from multiple endocrine neoplasia type 1 to familial isolated pituitary adenoma. Horm Res 2009, 71 (Suppl. 1): 105-11.

17. Bell DR, Poland A. Binding of aryl hydrocarbon receptor (AhR) to AhR-interacting protein. The role of hsp90. J Biol Chem 2000, 275: 36407-14.

18. Petrulis JR, Perdew GH. The role of chaperone proteins in the aryl hydrocarbon receptor core complex. Chem Biol Interact 2002, 141: 25-40.

19. Jaffrain-Rea ML, Angelini M, Gargano D, et al. Expression of aryl hydrocarbon receptor (AHR) and aryl hydrocarbon receptor interacting protein (AIP) in pituitary adenomas: pathological and clinical implications. Endocr Relat Cancer 2009, 16: 1029-43.

20. Peltonen L. Molecular background of the Finnish disease heritage. Ann Med 1997, 29: 553-6.

21. Vargiolu M, Fusco D, Kurelac I, et al. The tyrosine kinase receptor RET interacts in vivo with AIP to alter survivin availability. J Clin Endocrinol Metab 2009, 94: 2571-8.

22. Krawczak M, Ball EV, Cooper DN. Neighboring-nucleotide effects on the rates of germ-line single-base-pair substitution in human genes. Am J Hum Genet 1998, 63: 474-88.

23. Jennings J, Georgitsi M, Holdaway I, et al. Aggressive pituitary adenomas occurring in young patients in a large Polynesian kindred with a germline R271W mutation in the AIP gene. Eur J Endocrinol 2009, 161: 799-804.

24. Georgitsi M, Heliövaara E, Paschke R, et al. Large genomic deletions in AIP in pituitary adenoma predisposition. J Clin Endocrinol Metab 2008, 93: 4146-51.

25. Cazabat L, Guillaud-Bataille M, Bertherat J, Raffin-Sanson ML. Mutations of the gene for the aryl hydrocarbon receptor-interacting protein in pituitary adenomas. Horm Res 2009, 71: 132-41.

26. Khoo SK, Pendek R, Nickolov R, et al. Genome-wide scan identifies novel modifier loci of acromegalic phenotypes for isolated familial somatotropinoma. Endocr Relat Cancer 2009, 16: 1057-63.

27. Jaffrain-Rea ML, Tichomirowa M, Daly AF, Beckers A. Pituitary adenomas in young patients: when should we consider a genetic predisposition? Expert Rev Endocrinol Metab 2010, 4: 529.

28. Brandi ML, Gagel RF, Angeli A, et al. Guidelines for diagnosis and therapy of MEN type 1 and type 2. J Clin Endocrinol Metab 2001, 86: 5658-71. 